\title{
Dynamics of myogenic differentiation using a novel Myogenin knock-in reporter mouse
}

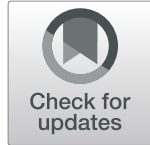

\author{
Maria Benavente-Diaz ${ }^{1,2,3}$, Glenda Comai ${ }^{1,2}$, Daniela Di Girolamo ${ }^{1,2}$, Francina Langa ${ }^{4}$ and Shahragim Tajbakhsh ${ }^{1,2^{*}}$ (D)
}

\begin{abstract}
Background: Myogenin is a transcription factor that is expressed during terminal myoblast differentiation in embryonic development and adult muscle regeneration. Investigation of this cell state transition has been hampered by the lack of a sensitive reporter to dynamically track cells during differentiation.

Results: Here, we report a knock-in mouse line expressing the tdTOMATO fluorescent protein from the endogenous Myogenin locus. Expression of tdTOMATO in Myog thtom mice recapitulated endogenous Myogenin expression during embryonic muscle formation and adult regeneration and enabled the isolation of the MYOGENIN ${ }^{+}$cell population. We also show that tdTOMATO fluorescence allows tracking of differentiating myoblasts in vitro and by intravital imaging in vivo. Lastly, we monitored by live imaging the cell division dynamics of differentiating myoblasts in vitro and showed that a fraction of the MYOGENIN ${ }^{+}$population can undergo one round of cell division, albeit at a much lower frequency than MYOGENIN ${ }^{-}$myoblasts.
\end{abstract}

Conclusions: We expect that this reporter mouse will be a valuable resource for researchers investigating skeletal muscle biology in developmental and adult contexts.

Keywords: Myogenin, Knock-in mouse, tdTOMATO, Intravital imaging, Skeletal muscle

\section{Background}

Embryonic and postnatal myogenesis and adult muscle regeneration are regulated by a family of basic helixloop-helix myogenic regulatory factors (MRFs) comprising Myf5, Mrf4, Myod and Myogenin (Myog). Following myogenic specification in the embryo, the MRFs are expressed in a sequential manner to ensure commitment, proliferation, differentiation and fusion to give rise to multinucleated skeletal myofibres. Single and combinatorial mouse knockout models of the MRFs have established a genetic hierarchy where Myf5, Mrf4 and Myod control lineage commitment and proliferation of myogenic progenitors, and Myod, Mrf4 and Myog regulate in terminal differentiation [1]. Notably, amongst the

\footnotetext{
* Correspondence: shahragim.tajbakhsh@pasteur.fr

${ }^{1}$ Stem Cells \& Development Unit, Institut Pasteur, 25 rue du Dr. Roux, 75015

Paris, France

${ }^{2}$ UMR CNRS 3738, Institut Pasteur, Paris, France

Full list of author information is available at the end of the article
}

single MRF knockout mice, only Myog-null homozygous animals die at birth due to severe skeletal muscle defects [1-3]. Thus, unlike the other myogenic bHLH factors, Myog has no redundant or compensatory mechanisms to replace its function during development. Myoblasts lacking this gene accumulate in the muscle-forming areas throughout the body and fail to form normal myofibers in vivo, pointing to its critical role in terminal differentiation of myoblasts [2-4]. While Myog-null embryos have some disorganised residual primary fibres, major differences between mutant and wild-type embryos become apparent during the initiation of secondary myofibre formation [2, 4]. Unexpectedly, conditional ablation of Myog during the perinatal and postnatal period does not result in noticeable defects in muscle morphology or histology, suggesting that $\mathrm{Myog}^{-/-}$myoblasts can still contribute to muscle growth $[5,6]$. Additionally, conditional ablation of Myog in a Duchenne muscular dystrophy mouse model $(m d x$ [7]) did not result in an 
adverse phenotype, confirming that Myog is dispensable for adult muscle regeneration in this disease [8]. Nevertheless, although Myog-null muscle stem cells (MuSCs) proliferate and differentiate in culture as efficiently as wild-type cells, the muscle gene expression program is profoundly altered in the absence of Myog [6].

Adult muscle regeneration depends on MuSCs, characterised by the expression of Pax7 [9-13]. Upon muscle injury, MuSCs activate the expression of Myod, proliferate to generate myoblasts that differentiate and fuse to form myofibres. Different reporter mouse lines have been generated to fluorescently label the $\operatorname{Pax} 7^{+}$muscle progenitor population, either from the endogenous locus [14-16] or as transgenes [15, 17, 18], thereby allowing imaging and isolation of Pax7-expressing cells. Additionally, inducible reporters in which expression of the Cre recombinase under the control of the $\operatorname{Pax} 7$ promoter recombines a membrane or cytoplasmic fluorophore [13, 19, 20] have been used for permanent marking of the myogenic lineage [21-23] and for live imaging [24]. Although several reporter mouse lines have been generated to identify differentiating myoblasts based on the expression of Myosin light chain [25], Myog [26-28] and Muscle creatine kinase [29], they are based on lacZ ( $\beta$ galactosidase activity, [30]) or cat (chloramphenicol acetyltransferase, [31]) expression and thus only allow endpoint measurements on fixed samples.

Terminal myoblast differentiation is characterised by the expression of Myog and the cyclin-dependent kinase inhibitor $p 21$ and cell cycle withdrawal [32-34]. Experiments using the nucleotide analogue BrdU have shown that MYOG-positive cells can undergo DNA replication [32], but it is still unclear how many divisions they can execute before definitively leaving the cell cycle.

Here, we took advantage of the CRISPR/Cas9 system, which allows precise genome editing [35], to generate a knock-in mouse line expressing a nuclear localised tandem-dimer Tomato (tdTOM) protein under the control of the endogenous Myog promoter, while retaining expression of MYOG protein. We show that heterozygous Myog ${ }^{\text {ntdTom }}$ mice exhibit robust reporter gene expression in fixed and live myogenic cells thus allowing in vitro and intravital microscopy studies of the dynamics of muscle differentiation and cell cycle withdrawal.

\section{Materials and methods}

\section{Mouse maintenance}

Animals were handled according to national and European Community guidelines and an ethics committee of the Institut Pasteur (CETEA, Comité d'Ethique en Expérimentation Animale) in France approved protocols (Licence 2015-0008). Except when indicated otherwise, males and females of 2-4 months were used.
Generation of the Myog-ntdTomato construct for CRISPRCas9-mediated homologous recombination

A fragment of $1000 \mathrm{bp}$ from the last exon of Myog was amplified by PCR from murine gDNA (primers 1 and 2, Supplementary Table 1), introducing SalI and NotI restriction sites. This fragment was subcloned into the donor plasmid encoding for tdTOM (kind gift from Dr. Festuccia, Institut Pasteur). A fragment of $760 \mathrm{bp}$ from the 3'UTR of the Myog gene just after the STOP codon was amplified by PCR from murine gDNA (primers 3 and 4). This amplification also introduced a mutation in the PAM sequence necessary for CRISPR-Cas9 genome editing. Using the PacI and SpeI restriction sites added, the fragment was subcloned into the PacI and $\mathrm{XbaI}$ digested tdTOM plasmid. Oligos containing a T2A (primers 5 and 6) [36] peptide and a triple NLS sequence from SV40 large $\mathrm{T}$ [37] were annealed and subcloned into a blunt pBluescript SK (+) plasmid. This plasmid was subsequently digested with NotI and KpnI and the T2A-NLS fragment was cloned into the tdTOM plasmid. tdTOM was amplified by PCR from the initial plasmid (primers 7 and 8) adding KpnI and FseI sites and subcloned into the donor vector after the $3 x N L S$ sequence. An FNF cassette containing two FRT sites and the NeoR/KanR gene under the control of the PGK promoter was amplified by PCR (primers 9 and 10) adding FseI and PacI sites. This fragment was subcloned into the donor vector.

The highest scoring sgRNA sequence to target the Myog STOP codon region was determined using a guide design tool (crispr.mit.edu, Zhang Lab). Primers containing this targeting sequence (primers 11 and 12) were annealed and subcloned into the pU6-(BbsI) CBh-Cas9T2A-mCherry vector (Addgene \#64324) digested with BbsI.

\section{Targeting of mouse embryonic stem cells}

The Myog-ntdTOM donor construct (linearised by PvuI digestion) and the pU6 vector were electroporated in C57BL/6J mouse embryonic stem cells. Following G418 $(300 \mu \mathrm{g} / \mathrm{ml})$ selection, positive clones were determined by PCR using primers 13, 14 and 15 (Supplementary Table 1), yielding a $1.7 \mathrm{~kb}$ band for the WT and $1.2 \mathrm{~kb}$ for the mutant. Two positive clones were expanded and 8-10 embryonic stem cells were injected into $B A L B / c$ blastocysts to generate chimeric mice in the Mouse Genetics Engineering Facility at the Institut Pasteur. Germline transmission was verified by PCR and F1 mice were crossed to $\mathrm{Tg}$ (ACTFLPe)9205Dym [38] animals to excise the FNF cassette. Excision of the FNF cassette and presence of the Myog ${ }^{\text {ntdTom }}$ allele was verified by PCR using primers 16, 17 and 18 (Supplementary Table 1) (Flprecombined Myog $g^{\text {ntdTom }}$ allele, $236 \mathrm{bp}$ and WT allele $600 \mathrm{bp}$, Figure S1), and these primers were subsequently 
used for genotyping. F2 animals were backcrossed to $C 57 B L / 6$ animals to eliminate the $T g$ (ACTFLPe) allele, and $M y o g^{\text {ntdTom/+ }}$ animals were selected for further characterisation.

\section{Isolation and culture of MuSCs}

Foetal and adult muscles were dissected and minced in ice-cold DMEM as described in [39]. Samples were then incubated in DMEM, 0.08\% Collagenase D (Sigma, 11088882001), 0.2\% Trypsin (ThermoFisher, 15090) and $10 \mu \mathrm{g} / \mathrm{ml}$ of DNAseI (Sigma, 11284932) for $25 \mathrm{~min}$ at $37^{\circ} \mathrm{C}$ under gentle agitation for 5 rounds of digestion. After each round, samples were allowed to sediment for $5 \mathrm{~min}$, the supernatant was collected in $4 \mathrm{ml}$ of foetal bovine serum (FBS) on ice and fresh digestion buffer was added to the remaining muscle pellet. The collected supernatants were centrifuged for $15 \mathrm{~min}$ at $550 \mathrm{~g}$ at $4{ }^{\circ} \mathrm{C}$, resuspended in DMEM 2\% FBS, and filtered through a $40-\mu \mathrm{m}$ strainer (Corning, 352235) before cell sorting. Cells were isolated based on size, granulosity and GFP or tdTOM fluorescence using an Aria III (BD Biosciences) flow cytometer. Cells were collected directly in MuSC growth media (38.5\% DMEM (Fisher Scientific, 31966047), 38.5\% F12 (Fisher Scientific, 31765035), 20\% FBS (ThermoFisher, 10270), 2\% Ultroser (Pall, 15950017), $1 \%$ penicillin/streptomycin (GIBCO, 15140-122)).

Matrigel $^{\circ}(1 \mathrm{mg} / \mathrm{ml}$, Corning, 354248) coated dishes $\left(30 \mathrm{~min}\right.$ at $37^{\circ} \mathrm{C}$ ) were used to culture MuSCs in growth media at $3 \% \mathrm{O}_{2}, 5 \% \mathrm{CO}_{2}, 37^{\circ} \mathrm{C}$ for the indicated times.

For immunostaining, cells were fixed in $4 \%$ paraformaldehyde (PFA, Electron Microscopy Sciences, 15710) in PBS for $15 \mathrm{~min}$ at room temperature (RT), permeabilised in $0.5 \%$ Triton X-100 (Merck, T8787) for 5 min at RT and blocked with $10 \%$ goat serum (GIBCO). Cells were incubated with the indicated primary antibodies in PBS 2\% goat serum buffer overnight following by 45 min incubation with secondary antibodies and $1 \mu \mathrm{g} / \mathrm{ml}$ Hoechst (ThermoFisher, H1399).

\section{Embryo immunofluorescence}

For tissue immunofluorescence, embryos were collected in PBS and fixed in 4\%PFA $0.1 \%$ Triton X-100 in PBS for $2 \mathrm{~h}$ at $4{ }^{\circ} \mathrm{C}$. After $3 \mathrm{PBS}$ washes, embryos were cryopreserved in 30\% sucrose in PBS and embedded in OCT tissue freezing media (Leica, 14020108926) for cryosectioning. Cryosections were allowed to dry for 30 min at room temperature and washed once with PBS. Tissue samples were blocked in 3\% BSA, 10\% goat serum, $0.5 \%$ Triton $\mathrm{X}-100$ for $1 \mathrm{~h}$ at room temperature. Primary antibodies were diluted in blocking solution and incubated overnight at $4{ }^{\circ} \mathrm{C}$. After three washes with PBST (PBS 0.1\% Tween20 (Sigma Aldrich, P1379)), secondary antibodies were diluted in blocking solution and incubated for $45 \mathrm{~min}$ at room temperature. Finally, samples were incubated with $1 \mu \mathrm{g} / \mathrm{ml}$ Hoechst 33342 for $5 \mathrm{~min}$ at room temperature to visualise nuclei, washed three times in PBS and mounted in $70 \%$ glycerol in PBS for imaging.

For whole-mount immunofluorescence, embryos were collected in PBS and fixed in 4\% PFA 0.1\% Triton X-100 for $2 \mathrm{~h}$ at $4{ }^{\circ} \mathrm{C}$. After two PBS washes, samples were dehydrated in 50\% methanol in PBS and kept in 100\% methanol at $-20^{\circ} \mathrm{C}$ until used. Samples were rehydrated in PBS and incubated in blocking buffer (15\% goat serum, $1.5 \%$ BSA, $0.5 \%$ TritonX-100 in $1 \mathrm{X}$ PBS) for $1 \mathrm{~h}$ at RT in 2-ml Eppendorf tubes. Embryos were then incubated with primary antibodies in the blocking buffer for 5-7 days at $4{ }^{\circ} \mathrm{C}$ with rocking. Embryos were washed extensively for $2-4 \mathrm{~h}$ in PBST and incubated in Fab' secondary antibodies for 2 days at $4{ }^{\circ} \mathrm{C}$ with rocking. Embryos were washed as above, dehydrated in 50\% methanol in PBS, twice in 100\% methanol and then cleared with BABB and mounted for imaging [40].

\section{Adult muscle injury, histology and immunofluorescence}

Muscle injury was done as described previously [22]. Mice were anaesthetised with $0.5 \%$ Imalgene/ $2 \%$ Rompun, and the TA muscle was injected with $50 \mathrm{ml}$ of cardiotoxin (10 mM; Latoxan, L8102) diluted in $0.9 \% \mathrm{NaCl}$.

Injured TA muscles were fixed upon harvesting in $4 \%$ PFA for $2 \mathrm{~h}$ at $4{ }^{\circ} \mathrm{C}$, washed with PBS and equilibrated with 30\% sucrose in PBS overnight. Samples were mounted in OCT tissue freezing media and cryosectioned between 8 and $12 \mu \mathrm{m}$. When endogenous tdTOM was scored, cryosections were rehydrated in PBS and counterstained with Hoechst 33342.

In case of MYOG plus tdTOM detection, tissue sections were processed for histology as described [41]. Briefly, sections were post-fixed in 4\% PFA for $10 \mathrm{~min}$ at RT and washed with PBS prior to immunostaining. Heat-induced epitope retrieval was performed in a citrate solution pH 6.0 during $6 \mathrm{~min}$ in a pressure cooker. Sections were then incubated with $30 \% \mathrm{H}_{2} \mathrm{O}_{2}$ for $5 \mathrm{~min}$ at RT. Samples were then permeabilised with $0.2 \%$ Triton-X100, washed in PBS and blocked in blocking buffer (15\% goat serum, 1.5\% BSA, 0.5\% TritonX-100 in 1X PBS). Primary antibodies against MYOG and DsRED (recognising tdTOM) were incubated overnight at $4{ }^{\circ} \mathrm{C}$. After washing with PBST, sections were incubated with appropriate secondary antibodies and $1 \mu \mathrm{g} / \mathrm{ml}$ Hoechst 33342 in blocking buffer for $45 \mathrm{~min}$ at RT (Table 1).

\section{Western blot}

Embryos were collected in ice-cold PBS and subsequently snap frozen in dry ice. Embryonic tissues were ground to a fine powder using a mortar and pestle on dry ice and lysed in RIPA buffer $(150 \mathrm{M} \mathrm{NaCl}, 50 \mathrm{mM}$ Tris pH 8, 5 mM EDTA, 1\% NP-40 (Sigma, I8896), 0.5\% sodium deoxycholate, $0.1 \%$ SDS supplemented with $1 \mathrm{X}$ 
Table 1 Antibodies used for immunostaining

\begin{tabular}{|c|c|c|c|}
\hline & Species & Concentration & Reference \\
\hline \multicolumn{4}{|l|}{ Primary antibodies } \\
\hline Myog & Mouse monoclonal (lgG1) & $1: 20$ & DHSB, clone F5D, supernatant \\
\hline Living colors ${ }^{\circledast}$ Ds-Red & Rabbit polyclonal & $1: 500$ & Takara Bio, 632496 \\
\hline Myosin heavy chain (MyHC) & $\begin{array}{l}\text { Mouse monoclonal } \\
\text { (lgG2b) }\end{array}$ & $1: 30$ & DHSB, MF-20, supernatant \\
\hline \multicolumn{4}{|l|}{ Secondary antibodies } \\
\hline Alexa Fluor ${ }^{\oplus} 88$ AffiniPure Goat Anti-Mouse $\lg G 1(\gamma 1)$ & Goat & $1: 500$ & $\begin{array}{l}\text { Jackson ImmunoResearch Labs, 115-545- } \\
205\end{array}$ \\
\hline $\begin{array}{l}\text { Alexa Fluor } 555 \text { F(ab')2 Fragment of Goat Anti-Rabbit } \\
\text { lgG }\end{array}$ & Goat & $1: 500$ & Thermo Fisher Scientific, A-21430 \\
\hline Alexa Fluor 633 Goat Anti-Mouse lgG2b (ү2b) & Goat & $1: 500$ & Thermo Fisher Scientific, A-21146 \\
\hline
\end{tabular}

protease (Sigma, S8820) and phosphatase inhibitors (Roche, 4906845001)). Fifteen microgrammes of protein extracts were run on a $4-12 \%$ Bis-Tris Gel NuPAGE (Invitrogen, NP0322) and transferred on a PVDF Amersham Hybond-P transfer membrane (GE Healthcare, RPN303F). The membrane was blocked with 5\% milk (Dominique Dutscher, 711160) in Tris-Buffer Saline 0.2\% Tween (Sigma, P9416) (TBS-T) for $1 \mathrm{~h}$ at room temperature and probed with specific primary antibodies overnight at $4{ }^{\circ} \mathrm{C}$. After three washes in TBS$\mathrm{T}$, the membrane was incubated with HRP or fluorophore-conjugated secondary antibodies and revealed by chemiluminescence (Pierce ECL2 western blotting substrate, Thermo Scientific, 80196) or fluorescence (Bio-Rad, Chemidoc MP) (Table 2).

\section{RNA extraction}

RNA from cells isolated by FACS was extracted using a Trizol-based kit (Zymo Research, R2061) and reverse transcribed using SuperScriptIII (Invitrogen, 18080093). RT-qPCR to assess for mRNA relative expression was performed with SYBR green master mix (Roche, 04913914001) in Applied biosciences machine. Data analysis was performed using the $2^{-\Delta \Delta C T}$ method [42] and mRNA expression was normalised with Rpl13 (primers 23 and 24, Supplementary Table 1).

\section{In vitro videomicroscopy}

MuSCs were plated on a microscopy culture chamber (IBIDI, 80826) and cultured in growth media supplemented as above. The plate was incubated at $37^{\circ} \mathrm{C}, 5 \%$ $\mathrm{CO}_{2}$ and $3 \% \mathrm{O}_{2}$ in a Pecon incubation chamber. A Zeiss Observer.Z1 connected to a Plan-Apochromat 20x/0.8 M27 objective and Hamamatsu Orca Flash 4 camera piloted with Zen software (Carl Zeiss) was used.

\section{Static imaging}

The following systems were used for image acquisition: Zeiss SteREO Discovery V20 for macroscopic observations of whole embryos and Zeiss LSM800 or LSM700 laser-scanning confocal microscopes for tissue sections and whole-mount immunostaining of cleared embryos. End point in vitro culture samples were imaged with a Zeiss Observer.Z1.

\section{Intravital microscopy}

Intravital imaging of Pax $7^{\mathrm{CreERT2}}$; $R 26^{\text {YFP }}$; Myog ${ }^{\text {ntdTom }}$ mice at different timepoints during regeneration was performed on an upright Nikon NiE A1R MP microscope piloted with NIS software (Nikon). The microscope was equipped with a $\times 25$ NA 1.1 PlanApo LambdaS objective, GaAsP PMT detectors and a Spectra-Physics Insight Deepsee laser. Laser frequency

Table 2 Antibodies used for Western blot

\begin{tabular}{llll}
\hline & Species & Concentration & Reference \\
\hline $\begin{array}{l}\text { Primary antibodies } \\
\text { Myog }\end{array}$ & Mouse monoclonal (lgG1) & $1: 500$ & DHSB, clone F5D, supernatant \\
Living colors ${ }^{\oplus}$ Ds-Red & Rabbit polyclonal & $1: 1000$ & Takara Bio, 632496 \\
$\begin{array}{l}\text { Secondary antibodies } \\
\text { Mouse-HRP }\end{array}$ & & Pierce, 31430 \\
Rabbit-HRP & Goat polyclonal & $1: 5000$ & Pierce, 31460 \\
GAPDH-Rhodamine & Goat polyclonal & $1: 5000$ & Bio-Rad, 12004168 \\
\hline
\end{tabular}




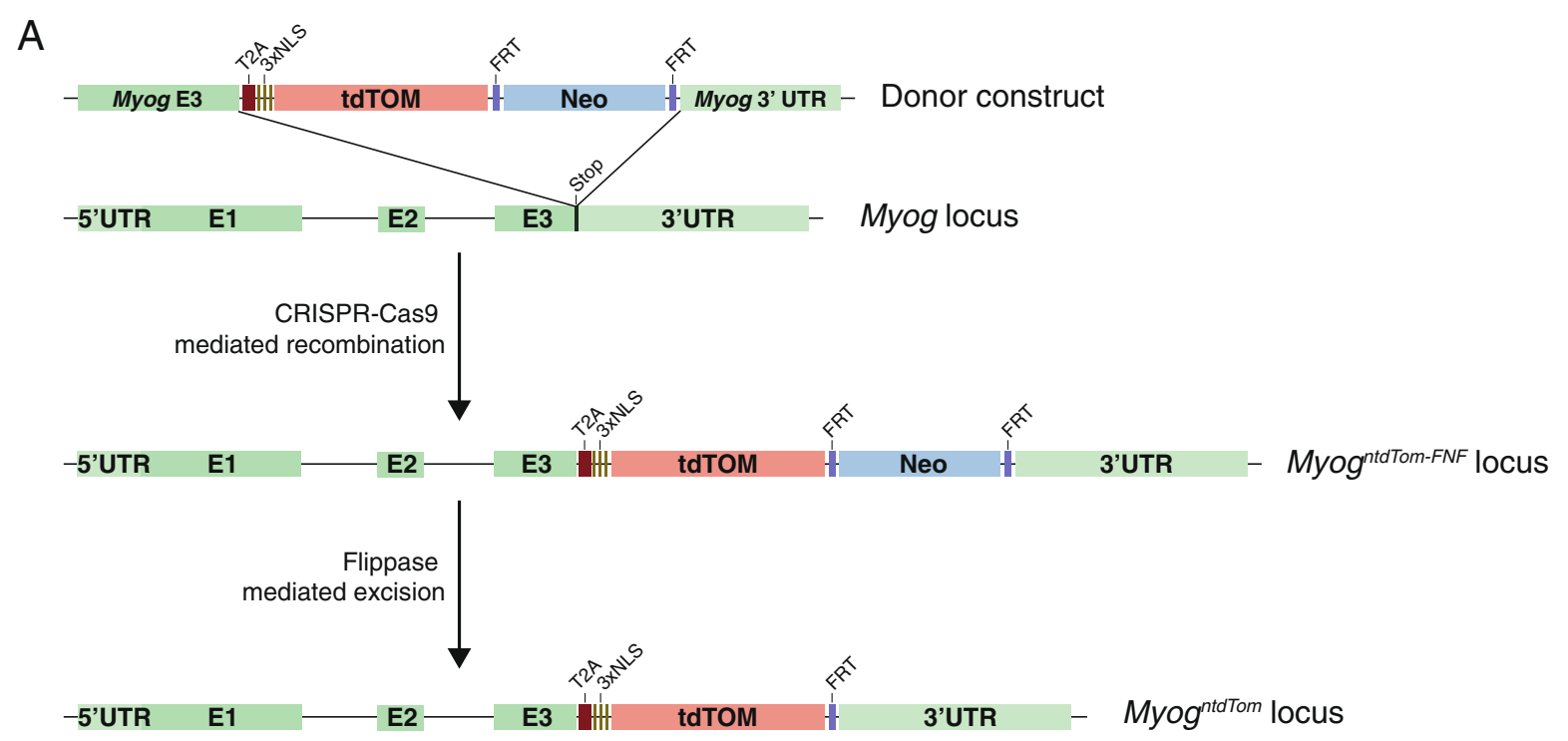

B

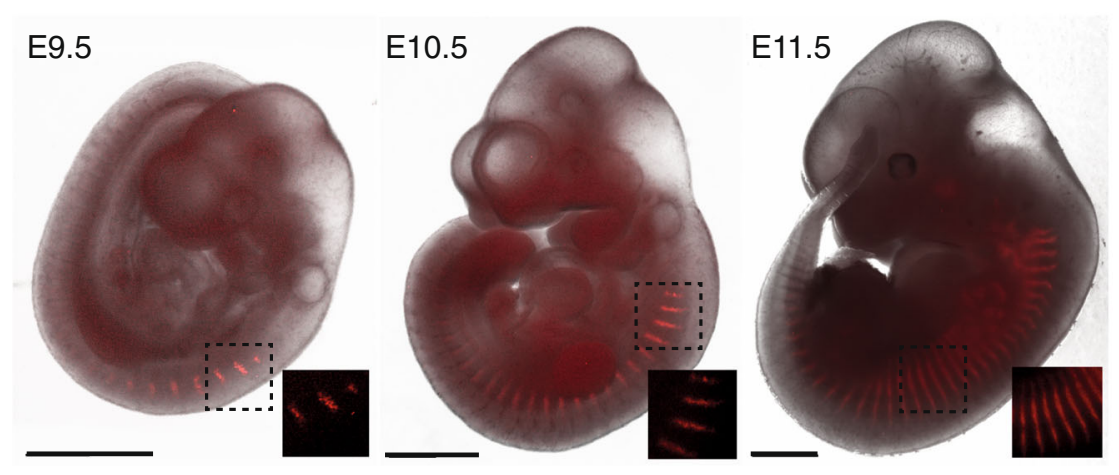

C
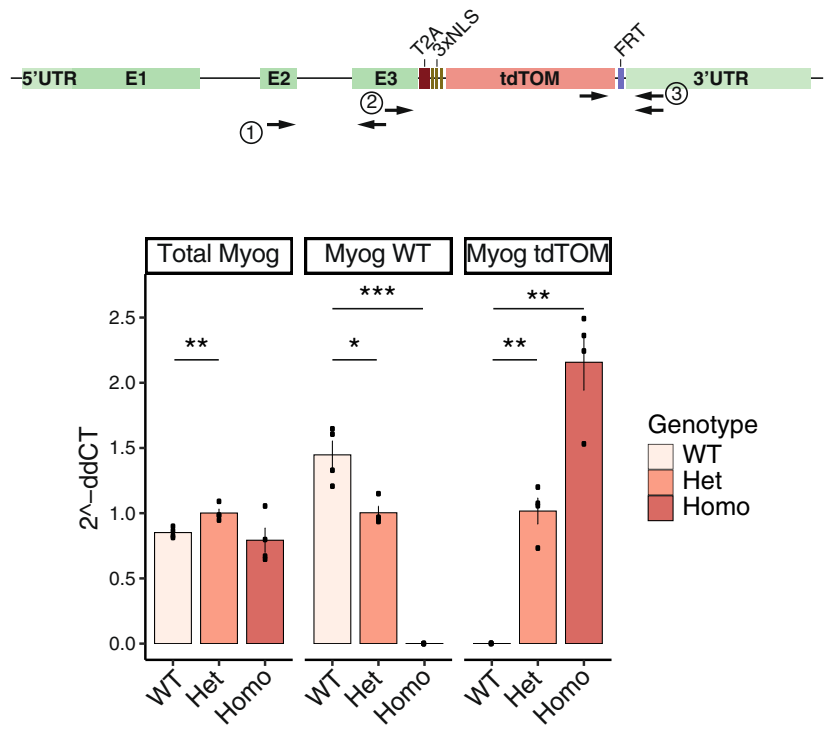

Fig. 1 (See legend on next page.)
D
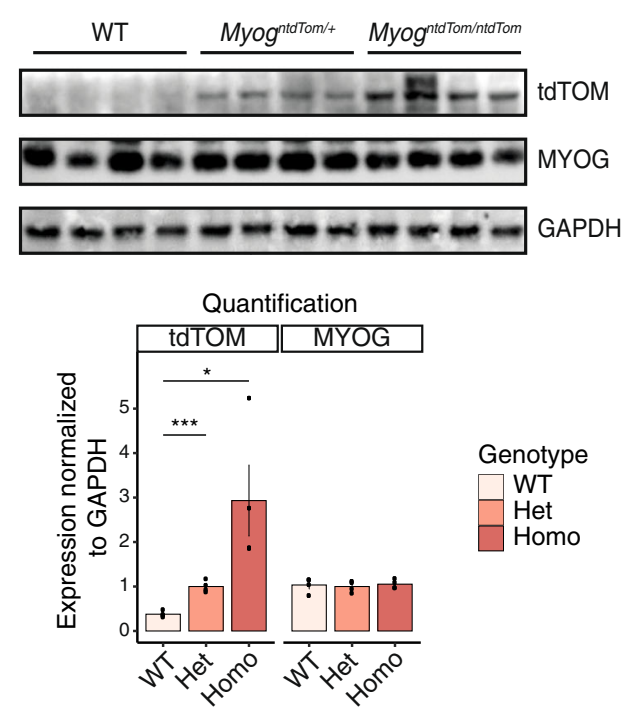
(See figure on previous page.)

Fig. 1 Generation of a Myog knock-in mouse line. a Scheme depicting the endogenous Myog locus, the donor construct and the result of the CRISPR-Cas9-mediated recombination in mouse embryonic stem cells. First-generation Myog ${ }^{\text {ntdTom-FNF }}$ mice were then crossed with a Tg(ACTF $(\mathrm{Pe})^{+/+}$deleter strain to excise the FNF cassette. $\mathbf{b}$ Endogenous fluorescence from $\mathrm{Myog}^{\text {ntdTom/+ }}$ embryos at different stages. An overlay between the brightfield and fluorescent images is shown. Scale bar, $1000 \mu \mathrm{m}$. c Scheme showing the primer pairs amplifying the wild-type allele (2), the ntdTom allele (3) and both alleles (1) in the targeted Myog locus. RT-qPCR analysis of the levels of total Myog mRNA, the wild-type allele and the tdTom allele specifically from E14.5 $\mathrm{Myog}^{+/+}$, Myog $^{\text {ntdTom/t }}$ and Myog $\mathrm{g}^{\text {ntdTom/ntdTom }}$ embryos. $n=4$ embryos per genotype. Data represents mean \pm s.d. Two-tailed unpaired Student's $t$ test; ${ }^{* * *} p$ value $<0.005$, ${ }^{* *} p$ value $=0.0005$ to $0.01,{ }^{*} p$ value $=0.01$ to 0.05 . $\mathbf{d}$ Western blot assessing the levels of MYOG and tdTOM proteins from E14.5 Myog ${ }^{+/+}$, Myog $^{\text {ntdTom } /+}$ and Myog ${ }^{\text {ntdTom/ntdTom }}$ embryos ( $n=4$ embryos per genotype). Bar graph shows the quantification of protein expression levels normalised to GAPDH. Data represents mean $\pm s$.d. Two-tailed unpaired Student's $t$ test; ${ }^{* * *} p$ value $<0.005,{ }^{*} p$ value $=0.01$ to 0.05

was tuned to $960 \mathrm{~nm}$ to allow simultaneous excitation of YFP and tdTOM fluorophores.

For image acquisition, the skin over the upper hindlimb was shaved and incised to expose approximately 1 $\mathrm{cm}^{2}$ of the muscle and imaged directly. During the imaging period, mice were anaesthetised with $1.5 \%$ isofluorane and maintained in an incubation chamber at $37^{\circ} \mathrm{C}$.

\section{Image analysis}

Cell tracking was performed using the Manual Tracking feature of the TrackMate plug-in [43] in Fiji [44]. ZEN software (Carl Zeiss), Fiji [44] and Imaris (Bitplane) were used for image analysis. Figures were assembled in Adobe Photoshop and Illustrator (Adobe Systems).

\section{Data analysis and statistics}

Data analysis and statistics were performed using R [45], and figures were produced using the package ggplot2 [46]. For comparison between two groups, two-tailed paired and unpaired Student's $t$ tests were performed to calculate $p$ values and to determine statistically significant differences (see figure legends).

\section{Results}

Generation and characterisation of a Myog ${ }^{\text {ntdTom }}$ mouse Using the CRISPR-Cas9 system, a sgRNA was designed to target the region of the STOP codon of the Myog gene for homologous recombination. The recombination template consisted of two homology arms corresponding to Myog sequences flanking the STOP codon, a $t d T o m$ coding sequence and a Neo resistance cassette flanked by frt sites (Fig. 1a). The tdTOM protein was preceded by a T2A peptide sequence [36] to allow cleavage from the MYOG protein following translation, and a triple NLS sequence [37] to ensure nuclear localisation.

First, we evaluated the endogenous tdTOM fluorescence in heterozygous Myog ${ }^{\text {ntdTom/+ }}$ embryos between E9.75 and E11.5 at the level of the somites, i.e. transient embryonic structures arising from the segmentation of the paraxial mesoderm. Endogenous tdTOM fluorescence followed a similar pattern to that described for
Myog transcripts [47] (Fig. 1b), with expression levels being lower in the caudal (more recently formed) somites.

We then collected tissue samples from E14.5 foetuses and performed RT-qPCR and Western blot analysis to confirm that Myog mRNA and protein levels were similar in wild-type, heterozygous and homozygous animals. Primer pairs were designed to amplify specifically the wild-type allele or the $t d$ Tom allele, and one primer set amplified both (Fig. 1c). This analysis showed that Myog heterozygous and homozygous knock-in (KI) embryos expressed similar levels of total Myog mRNA, and confirmed that no Myog wild-type transcript could be detected in the homozygous embryos. As expected, the levels of Myog ${ }^{\text {ntdTom }}$ mRNA were the highest in homozygous samples, decreased to roughly $50 \%$ in the case of the heterozygous and were not detected in wild-type embryos (Fig. 1c). At the protein level, we noted similar expression levels of MYOG in embryos from all three genotypes, whereas the tdTOM protein was absent in wild-type samples (Fig. 1d). Therefore, we conclude that MYOG protein was generated from transcripts that originated from both alleles.

To investigate the expression of the targeted allele with higher resolution, we assessed the temporal expression dynamics of MYOG and TdTOM proteins by whole-mount immunostaining at E10.5 and compared the expression of MYOG and tdTOM in wild-type, heterozygous and homozygous embryos (Fig. 2a, Additional files 1, 2, 3). We confirmed that tdTOM followed the expression pattern of MYOG in the epaxial and hypaxial domains of all somites, indicating that both proteins have similar spatiotemporal expression dynamics. To assess the co-expression of MYOG and tdTOM at the single cell level in heterozygous embryos, cryosections at the level of extraocular, tongue and limb muscles were examined during primary (E12.5) and secondary (E14.5) myogenesis when small oligo-nucleated and larger multi-nucleated myofibres are generated, respectively. Quantification of protein expression in different muscles confirmed an average co-localisation of both proteins in $97 \%$ and 95\% of the cells at E12.5 (Fig. 2b) and E14.5 (Figure $\mathrm{S} 2 \mathrm{~A})$, respectively. 


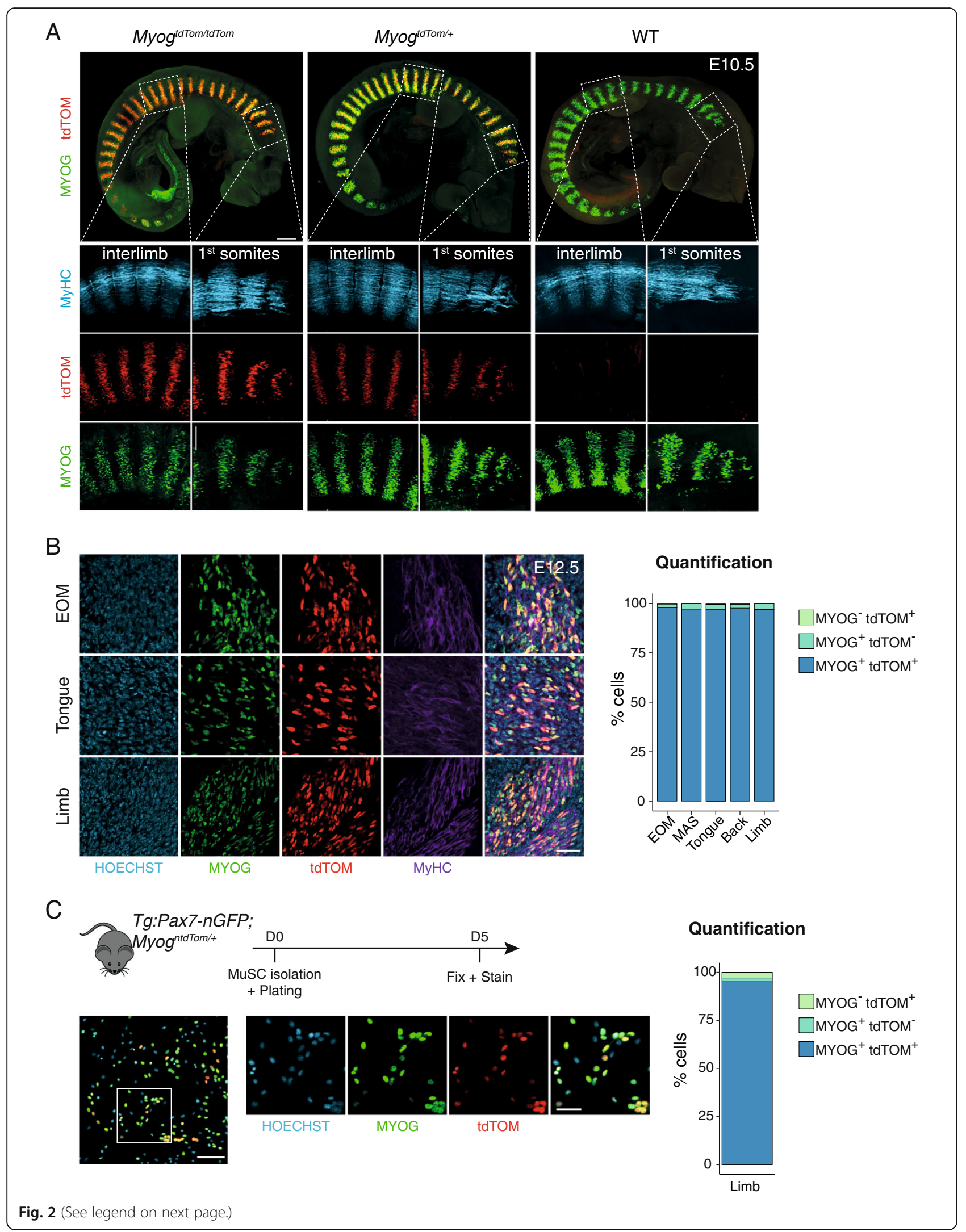


(See figure on previous page.)

Fig. 2 tdTOM expression recapitulates endogenous Myog expression. a Whole-mount immunofluorescence from $\mathrm{Myog}^{+/+}, \mathrm{Myog}^{\text {ntdTom/+ }}$ and Myog ${ }^{\text {ntdTom/ntdTom }}$ embryos at E10.5 stained for tdTOM, MYOG and MyHC proteins. Scale bar, $300 \mu \mathrm{m}$ on upper panels and $100 \mu \mathrm{m}$ on lower insets. b Immunofluorescence of extraocular (EOM), tongue and limb muscle cryosections of Myog ${ }^{\text {ntdTom/t }}$ embryos at E12.5. The bar graph shows the quantification of tdTOM- and MYOG-positive cells. $n=3$ embryos, $>100$ cells per muscle and per embryo were counted. Scale bar, $40 \mu m$. $\mathbf{c}$ MuSCs were isolated from limb muscles of Tg:Pax7-nGFP; Myog ${ }^{\text {ntdTom }}$ adult animals and plated for in vitro differentiation for 5 days. Bar graph shows the quantification of tdTOM- and MYOG-positive cells ( $n=3,>200$ cells per animal counted). Scale bar, $100 \mu \mathrm{m}$ on the left image, $50 \mu \mathrm{m}$ on the right inset

To assess the fidelity of the reporter mouse in adult myoblasts, Myog ${ }^{\text {ntdTom }}$ animals were crossed with $T g$ : Pax7-nGFP mice, where GFP marks all MuSCs [15]. MuSCs were isolated by FACS based on GFP expression, then differentiated in vitro for 5 days. In agreement with our results in the embryo, MYOG and tdTOM expression co-localised in about $95 \%$ of the cells (Fig. 2c). Additionally, no significant differences were observed in total Myog RNA levels between wild-type, heterozygous and homozygous animals (Figure S2B).

As indicated above, the KI strategy was designed to be non-disruptive and allow normal MYOG protein expression from the recombined alleles. Given that Myog-null mice are lethal at birth, and our Myog $g^{\text {ntdTom/ntdTom }}$ knock-in mice are viable, we propose that sufficient levels of MYOG are produced from the targeted allele. Nonetheless, a decrease in MYOG intensity was detected by immunofluorescence in homozygous Myog ${ }^{\text {ntdTom/ntd- }}$ Tom embryos and in vitro myoblast cultures from homozygous animals (Fig. 2a, Figure S2C). As this decrease was not observed in heterozygous samples, we decided to use heterozygous animals in our subsequent experiments.

In summary, tdTOM faithfully recapitulates the expression of MYOG protein in embryonic and adult muscle, and its insertion at the Myog locus does not impair significantly the expression of this gene at the mRNA and protein level.

\section{Myog ${ }^{\text {ntdTom }}$ mice allow isolation of differentiating myoblasts during development and regeneration}

To assess the expression of tdTOM in homeostatic conditions by flow cytometry, we isolated the mononuclear population from limb muscles of $\mathrm{Myog}^{\text {ntdTom/t }}$ mice at foetal (embryonic day (E) 18.5), postnatal (postnatal day (p) 21) and adult (10 weeks) stages. tdTOM fluorescent cells were detected at foetal and early postnatal stages where myogenesis was still taking place. In adult muscles in homeostasis, the majority of MuSCs are quiescent and therefore no $\mathrm{MYOG}^{+}$mono-nucleated cells are detectable [48]. As expected, virtually no tdTOM ${ }^{+}$cells were detected in muscles of adult Myog ${ }^{\text {ntdTom/t }}$ animals (Fig. 3a).

To determine if tdTOM followed the expression dynamics of MYOG during adult muscle regeneration, we performed an injury of the Tibialis anterior (TA) muscle of Tg:Pax7-nGFP; Myog $g^{\text {ntdTom/t }}$ mice by intramuscular injection of the snake venom toxin cardiotoxin [49]. We next performed FACS analysis to determine whether the $\mathrm{tdTOM}^{+}$mononucleated fraction could be isolated following tissue injury. As expected, only a few tdTOM ${ }^{+}$ cells were detected at 3 days post-injury, when myogenic cells are known to be maximally proliferating $[23,24$, 50] (Fig. 3b). td $\mathrm{TOM}^{+}$cells were most abundant at 5 and 10 days post-injury, corresponding to the increased shift towards differentiation of the transiently amplifying myoblast population during this period. As the major features of the regeneration process are completed by $3-$ 4 weeks, the proportion of $\mathrm{tdTOM}^{+}$cells decreased by 21 days post-injury, corresponding to the progressive return to quiescence of the myogenic population (Fig. 3b). Finally, to verify whether the $\operatorname{tdTOM}^{+}$cells isolated by FACS corresponded to myoblasts that expressed MYOG, we isolated the $\operatorname{tdTOM}^{+}$population from regenerating TA muscle at 5 days post-injury. Fixation of cells immediately after sorting and staining for MYOG and tdTOM showed that $95 \%$ of isolated cells were positive for MYOG (Fig. 3c), thereby confirming that tdTOM followed the expression dynamics of MYOG also during adult muscle regeneration and that its expression allows the isolation of $\mathrm{MYOG}^{+}$cells by FACS after injury.

Taken together, our results show that the Myog ${ }^{\text {ntdTom }}$ KI mouse allows efficient isolation of the $\mathrm{MYOG}^{+}$population at different stages during development as well as from regenerating muscle.

\section{Dynamics of $M y o g$ expression during terminal differentiation}

To assess if Myog-expressing myoblasts can execute a cell division, we took advantage of the tdTOM reporter to monitor Myog expression by live videomicroscopy of primary myoblasts in vitro. MuSCs from adult Tg:Pax7-nGFP; Myog ${ }^{\text {ntdTom } /+}$ mice were isolated by FACS based on GFP fluorescence and plated for in vitro differentiation. After 3 days of culture, live imaging was initiated and images were acquired every $9 \mathrm{~min}$ for $48 \mathrm{~h}$ (Fig. 4a, Additional File 4).

By manually tracking individual cells and monitoring their differentiation status based on tdTOM fluorescence, we observed that up to $35 \%$ of $\mathrm{MYOG}^{+}$cells 


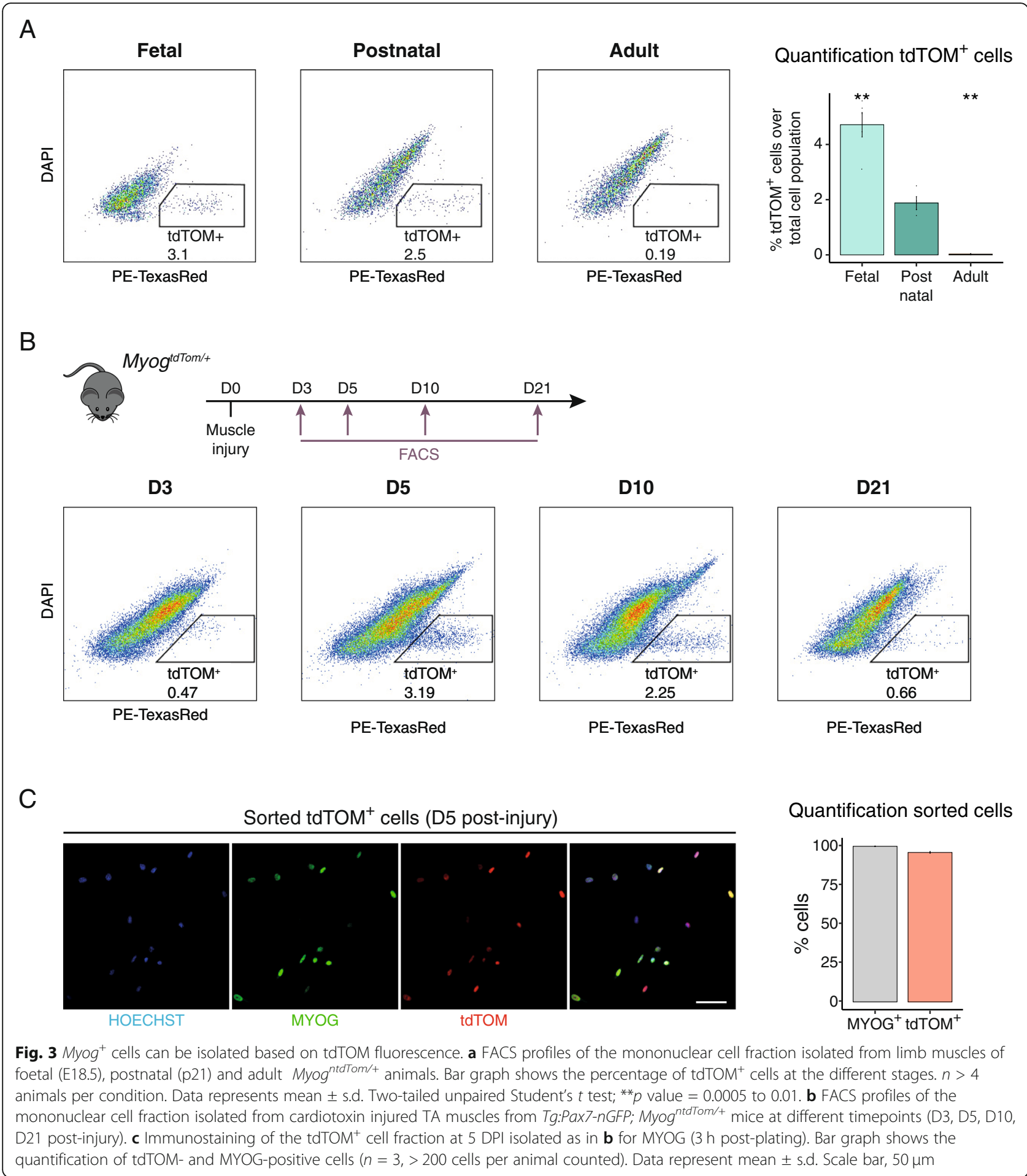

underwent cell division during the imaging period (Fig. 4b, c). Having established that $\mathrm{MYOG}^{+}$cells remain competent for cell division, we sought to quantify the number of divisions that they performed. Amongst all the $\mathrm{MYOG}^{+}$cells tracked, none divided more than once. In contrast, all $\mathrm{MYOG}^{-}$cells divided during the imaging period and performed 1.5 divisions on average during this time (Fig. 4c). Therefore, using the Myog ${ }^{\text {ntdTom }}$ reporter mouse, we show that about one third of $\mathrm{MYOG}^{+}$ cells can undergo one more cell division when tracking tdTOM expression.

Finally, we assessed the potential of the Myog $g^{\text {ntdTom }}$ mouse to monitor tissue regeneration by intravital imaging. Pax $7^{\mathrm{CreERT2} /+} ; \mathrm{R}^{\mathrm{Y} 6^{\mathrm{YFP} /+}} ; \mathrm{Myog}^{\text {ntdTom } /+}$ mice were 


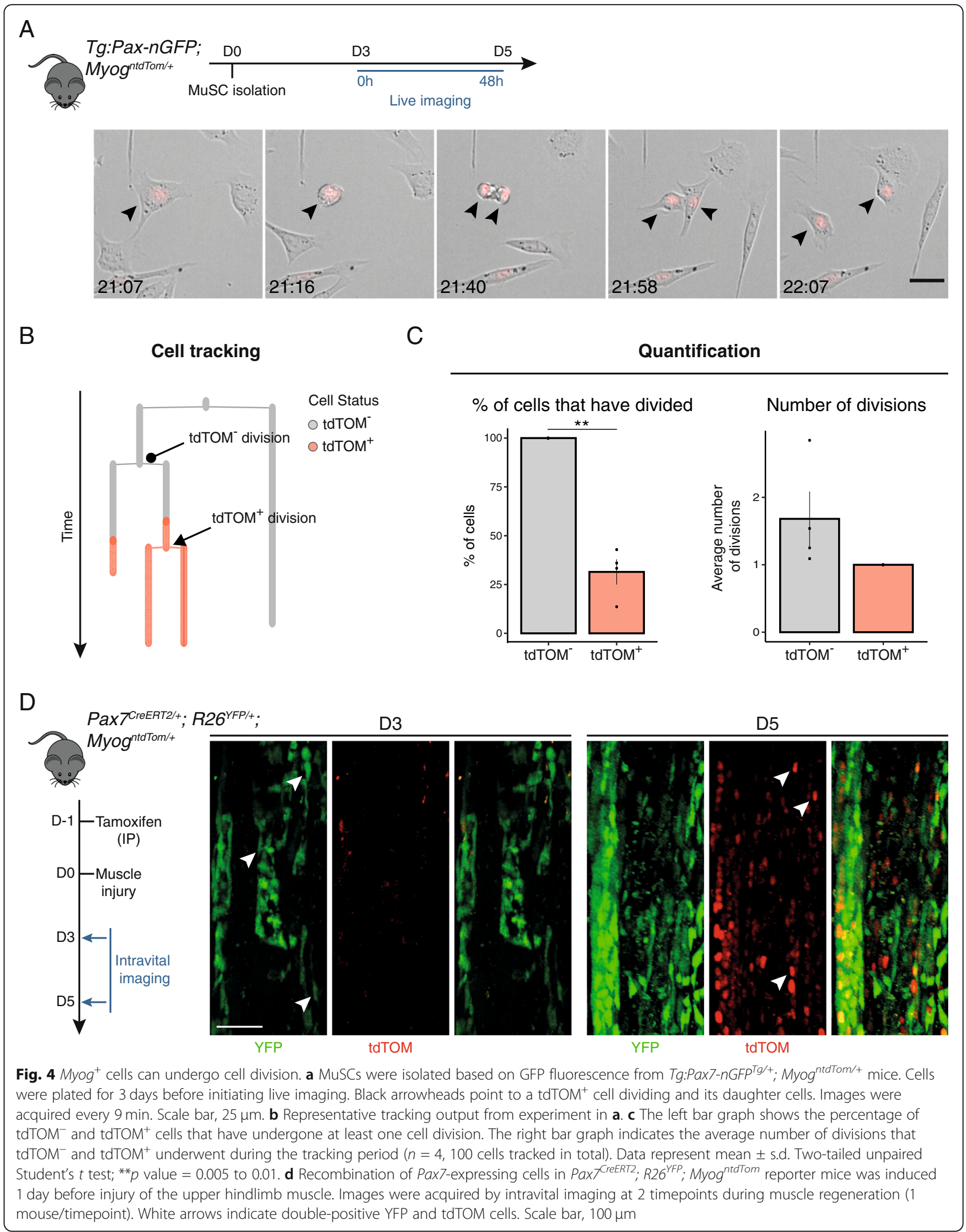


used to permanently label Pax7-expressing cells and their progeny upon tamoxifen administration and simultaneously trace the differentiated fraction by following tdTOM expression. We induced muscle injury by cardiotoxin injection in the upper hindlimb and monitored the regeneration process by live intravital imaging at different time points (Fig. 4d). As expected, few MYOG ${ }^{+}$ cells were detected at 3 days post-injury, when extensive proliferation of $\mathrm{YFP}^{+}$myogenic progenitor cells was taking place (Fig. 4d, left panels). Two days later, the population of $\mathrm{tdTOM}^{+}$myoblasts had significantly expanded and $\mathrm{tdTOM}^{+}$cells could be observed throughout the regenerating area (Fig. 4d, right panels, white arrows), recapitulating the results of our flow cytometry analysis.

Taken together, these experiments demonstrate that tdTOM is a robust reporter that allows monitoring of $\mathrm{MYOG}^{+}$cells by in vitro and intravital imaging.

\section{Discussion}

Myog is a critical regulator of myoblast differentiation and fusion, being an essential factor for embryonic muscle development. In the present study, we generated and characterised a novel mouse line to fluorescently label $\mathrm{MYOG}^{+}$cells by expression of the robust nuclear localised tdTOM protein from the endogenous Myog locus.

To characterise the properties of $\mathrm{tdTOM}^{+}$cells, we assessed its co-localisation with MYOG during embryonic and foetal development, in adult primary myogenic cells in vitro and during adult muscle regeneration in vivo. Given that in all conditions virtually all cells were positive for both markers (>95\% cells), we conclude that tdTOM reliably labels $\mathrm{MYOG}^{+}$cells from development to adulthood. Furthermore, total Myog levels from Myog ${ }^{\text {ntdTom/+ }}$ animals were comparable to that of the WT, and homozygous Myog $g^{\text {ntdTom/ntdTom }}$ mice are viable. Moreover, the expression of tdTOM allowed us to isolate the $\mathrm{MYOG}^{+}$ population from developing embryos as well as adult regenerating muscle indicating the utility of this reporter mouse in isolating living differentiating myoblasts that were previously inaccessible for direct investigation.

In addition, studies on the cell cycle dynamics of $\mathrm{Myog}^{+}$cells have been hampered by the lack of a fluorescent reporter. Here, by means of live microscopy and single-cell tracking of differentiating primary myoblasts, we demonstrated that about one third of $\mathrm{MYOG}^{+}$cells can divide in vitro and undergo a maximum of one additional cell division during the tracking period. Therefore, the majority of cells that express detectable levels of MYOG exit the cell cycle.

Several studies have performed intravital imaging of muscle tissue [24, 51-53]; however, only two of them dynamically monitored the process of muscle regeneration [24, 51]. These two studies focused on the progenitor population by labelling $\mathrm{PAX}^{+}$cells, but they did not report on the dynamics of differentiation. Here, we carried out proof-of-concept experiments by intravital imaging of adult regenerating muscle and showed that tdTOM fluorescence is sufficient to follow $\mathrm{MYOG}^{+}$ cells throughout the regeneration process.

\section{Conclusion}

In this study, we describe the creation of a new mouse line where tdTOM is expressed from the endogenous Myog locus. tdTOM faithfully recapitulates MYOG expression during embryonic development and adult muscle regeneration and it can be used to isolate this population by flow cytometry. Additionally, heterozygous tdTOM expression is sufficient for monitoring Myog dynamics by in vivo intravital imaging. Therefore, the Myog $g^{\text {ntdTom }}$ line can be of great benefit to study the dynamics of lineage progression of muscle progenitors in embryonic and adult stages.

\section{Supplementary Information}

The online version contains supplementary material available at https://doi. org/10.1186/s13395-021-00260-x.

\section{Additional file 1 Related to Fig. 2a. Whole mount immunofluorescence from a Myog $^{+/+}$embryo at E10.5 stained for tdTOM, MYOG and MyHC} proteins.

Additional file 2 Related to Fig. 2a. Whole mount immunofluorescence from a Myog ${ }^{\text {ntdTom/t }}$ and embryo at E10.5 stained for tdTOM, MYOG and $\mathrm{MyHC}$ proteins.

Additional file 3 Related to Fig. 2a. Whole mount immunofluorescence from a Myog ${ }^{\text {ntdTom/ntdTom }}$ embryo at E10.5 stained for tdTOM, MYOG and MyHC proteins.

Additional file 4 Related to Fig. 4a. In vitro division of a $\operatorname{tdTOM}^{+}$cell.

Additional file 5: Figure S1. Genotyping of the ntdTom allele. A. Genotyping of ear-clip samples from Myog ${ }^{\text {ntdTom/ntdTom }}$, Myog $^{\text {ntdTom/t }}$ and Myog $^{+/+}$animals. Myog-ntdTom allele was verified by PCR using primers 16, 17 and 18 (Flp-recombined Myog-ntdTom allele, $236 \mathrm{bp}$ and WT allele 600 bp).

Additional file 6: Figure S2. tdTOM expression recapitulates endogenous Myog expression. A. Immunofluorescence of extraocular (EOM), tongue and limb muscles of Myog ntdTom/t $^{\text {embryo at }}$ E14.5. Bar graph shows the quantification of tdTOM and MYOG positive cells. $\mathrm{n}=3$ embryos, $>100$ cells per muscle and per embryo were counted. Scale bar, $40 \mu \mathrm{m}$. B. RT-qPCR assessing the levels of total Myog $\mathrm{mRNA}$, the wild-type allele and the tdTom allele specifically from $\mathrm{Myog}^{+/+}$ Myog ${ }^{\text {ntdTom } /+}$ and Myog ${ }^{\text {ntdTom/ntdTom }}$ adult myoblasts using the primer set described in Fig. 1c. $n=3$ animals per genotype. Data represents mean \pm s.d. Two-tailed unpaired Student's t-test; ${ }^{*} p$-value $=0.01$ to 0.05 . C. MuSCs from limb muscles were isolated from Tg:Pax7-nGFP; Myog ${ }^{+/+}$

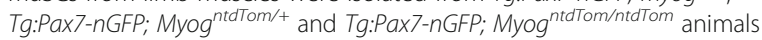
and plated for in vitro differentiation for 5 days. Cells were stained for MYOG and tdTOM proteins. Scale bar, $100 \mu \mathrm{m}$.

Additional file 7: Supplementary Table 1. Primer sequences

\section{Abbreviations}

Myog: Myogenin; MRF: Myogenic regulatory factor; MuSC: Muscle stem cell; BrdU: 5-Bromo-2'-deoxyuridine; sgRNA: Single guide RNA; CRISPR: Clustered regularly interspaced short palindromic repeats; NLS: Nuclear localisation sequence; GFP: Green fluorescent protein; RT-qPCR: Real-time quantitative polymerase chain reaction; KI: Knock-in; FACS: Fluorescence-assisted cell sorting; TA: Tibialis anterior; YFP: Yellow fluorescent protein 


\section{Acknowledgements}

We gratefully acknowledge S. Paisant for help with the maintenance of mouse embryonic stem cell lines, the Institut Pasteur Mouse Genetics Engineering Platform, the UtechS Photonic Biolmaging (Imagopole) at Institut Pasteur supported by the French National Research Agency (France Biolmaging; ANR-10-INSB-04; Investments for the Future), the Center for Translational Science (CRT)-Cytometry and Biomarkers Unit of Technology and Service (CB UTechS) at Institut Pasteur and the Nikon Imaging Center at Institut Curie-CNRS for support in conducting this study.

\section{Authors' contributions}

MBD designed, performed the experiments and analysed the data. GC, DDG and FL performed some experiments. ST designed and supervised the project. MBD and ST interpreted the data and wrote the manuscript. Al authors edited the manuscript. All authors read and approved the final manuscript.

\section{Funding}

We acknowledge funding support from the Institut Pasteur, Agence Nationale de la Recherche (Laboratoire d'Excellence Revive, Investissement d'Avenir; ANR-10-LABX-73), Association Française contre les Myopathies (Grant \#20510), and the Centre National de la Recherche Scientifique. M.B.D. was supported by a grant from Laboratoire d'Excellence Revive and La Ligue Contre le Cancer.

\section{Availability of data and materials}

All data generated and analysed during the study are available from the corresponding author on a reasonable request.

\section{Ethics approval and consent to participate}

Animals were handled according to national and European Community guidelines and an ethics committee of the Institut Pasteur (CETEA) in France approved protocols (Protocol\# 2015-0008).

\section{Consent for publication}

All authors have read the final version of the manuscript and consented to its submission to Skeletal Muscle.

\section{Competing interests}

The authors declare no competing interests.

\section{Author details}

${ }^{1}$ Stem Cells \& Development Unit, Institut Pasteur, 25 rue du Dr. Roux, 75015 Paris, France. ${ }^{2}$ UMR CNRS 3738, Institut Pasteur, Paris, France. ${ }^{3}$ Sorbonne Universités, Complexité du Vivant, F-75005 Paris, France. ${ }^{4}$ Mouse Genetics Engineering Center, Institut Pasteur, Paris, France.

\section{Received: 26 November 2020 Accepted: 6 January 2021} Published online: 18 February 2021

\section{References}

1. Comai G, Tajbakhsh S. Molecular and cellular regulation of skeletal myogenesis. Curr Top Dev Biol. 2014;110:1-73 https://doi.org/10.1016/b9780-12-405943-6.00001-4.

2. Nabeshima Y, Hanaoka K, Hayasaka M, Esuml E, Li S, Nonaka I, et al. Myogenin gene disruption results in perinatal lethality because of severe muscle defect. Nature. 1993;364:532-5 https://doi.org/10.1038/364532a0.

3. Hasty P, Bradley A, Morris JH, Edmondson DG, Venuti JM, Olson EN, et al. Muscle deficiency and neonatal death in mice with a targeted mutation in the myogenin gene. Nature. 1993;364:501-6 https://doi.org/10.1038/ $364501 \mathrm{a0}$.

4. Venuti JM, Morris JH, Vivian JL, Olson EN, Klein WH. Myogenin is required for late but not early aspects of myogenesis during mouse development. J Cell Biology. 1995;128:563-76 https://doi.org/10.1083/jcb.128.4.563.

5. Knapp JR, Davie JK, Myer A, Meadows E, Olson EN, Klein WH. Loss of myogenin in postnatal life leads to normal skeletal muscle but reduced body size. Development. 2006;133:601-10 https://doi.org/10.1242/dev.02249.

6. Meadows E, Cho J-H, Flynn JM, Klein WH. Myogenin regulates a distinct genetic program in adult muscle stem cells. Dev Biol. 2008;322:406-14 https://doi.org/10.1016/j.ydbio.2008.07.024.
7. Bulfield G, Siller WG, Wight PA, Moore KJ. X chromosome-linked muscular dystrophy (mdx) in the mouse. Proc National Acad Sci. 1984;81:1189-92 https://doi.org/10.1073/pnas.81.4.1189.

8. Meadows E, Flynn JM, Klein WH. Myogenin regulates exercise capacity but is dispensable for skeletal muscle regeneration in adult mdx mice. Plos One. 2011;6:e16184 https://doi.org/10.1371/journal.pone.0016184.

9. Seale P, Sabourin L a, Girgis-Gabardo a, Mansouri a, Gruss P, Rudnicki M a. Pax7 is required for the specification of myogenic satellite cells. Cell. 2000; 102:777-86 https://doi.org/10.1016/s0092-8674(00)00066-0.

10. Oustanina S, Hause G, Braun T. Pax7 directs postnatal renewal and propagation of myogenic satellite cells but not their specification. Embo J. 2004;23:3430-9 https://doi.org/10.1038/sj.emboj.7600346.

11. Lepper C, Partridge TA, C-MMC-M F. An absolute requirement for Pax7positive satellite cells in acute injury-induced skeletal muscle regeneration. Development. 2011;138:3639-46 https://doi.org/10.1242/dev.067595.

12. Sambasivan R, Yao R, Kissenpfennig A, Wittenberghe LV, Paldi A, GayraudMorel B, et al. Pax7-expressing satellite cells are indispensable for adult skeletal muscle regeneration. Development. 2011;138:3647-56 https://doi. org/10.1242/dev.067587.

13. Murphy MM, Lawson JA, Mathew SJ, Hutcheson DA, Kardon G. Satellite cells, connective tissue fibroblasts and their interactions are crucial for muscle regeneration. Development. 2011;138:3625-37 https://doi.org/10. 1242/dev.064162.

14. Kitajima Y, Ono Y. Visualization of PAX7 protein dynamics in muscle satellite cells in a YFP knock-in-mouse line. Skelet Muscle. 2018;8:26 https://doi.org/ 10.1186/s13395-018-0174-X.

15. Sambasivan R, Gayraud-Morel B, Dumas G, Cimper C, Paisant S, Kelly RG, et al. Distinct regulatory cascades govern extraocular and pharyngeal arch muscle progenitor cell fates. Dev Cell. 2009;16:810-21 https://doi.org/10. 1016/j.devcel.2009.05.008.

16. Sambasivan R, Comai G, Roux IL, Gomès D, Konge J, Dumas G, et al. Embryonic founders of adult muscle stem cells are primed by the determination gene Mrf4. Dev Biol. 2013;381:241-55 https://doi.org/10.1016/ j.ydbio.2013.04.018.

17. Bosnakovski D, Xu Z, Li W, Thet S, Cleaver O, Perlingeiro RCR, et al. Prospective isolation of skeletal muscle stem cells with a Pax7 reporter. Stem Cells. 2008;26:3194-204 https://doi.org/10.1634/stemcells.2007-1017.

18. Tichy ED, Sidibe DK, Greer CD, Oyster NM, Rompolas P, Rosenthal NA, et al. A robust Pax7EGFP mouse that enables the visualization of dynamic behaviors of muscle stem cells. Skelet Muscle. 2018;8:27 https://doi.org/10. 1186/s13395-018-0169-7.

19. Lepper C, Conway SJ, Fan C-M. Adult satellite cells and embryonic muscle progenitors have distinct genetic requirements. Nature. 2009;460:627-31 https://doi.org/10.1038/nature08209.

20. Mourikis P, Sambasivan R, Castel D, Rocheteau P, Bizzarro V, Tajbakhsh S. A critical requirement for Notch signaling in maintenance of the quiescent skeletal muscle stem cell state. Stem Cells. 2012;30:243-52 https://doi.org/ 10.1002/stem.775

21. Addicks GC, Brun CE, Sincennes M-C, Saber J, Porter CJ, Stewart AF, et al. MLL1 is required for PAX7 expression and satellite cell self-renewal in mice. Nat Commun. 2019;10:4256 https://doi.org/10.1038/s41467-019-12086-9.

22. Baghdadi MB, Firmino J, Soni K, Evano B, Girolamo DD, Mourikis P, et al. Notch-induced miR-708 antagonizes satellite cell migration and maintains quiescence. Cell Stem Cell. 2018;23:859-868.e5 https://doi.org/10.1016/j. stem.2018.09.017.

23. Evano B, Khalilian S, Carrou GL, Almouzni G, Tajbakhsh S. Dynamics of asymmetric and symmetric divisions of muscle stem cells in vivo and on artificial niches. Cell Reports. 2020;30:3195-3206.e7 https://doi.org/10.1016/j. celrep.2020.01.097.

24. Webster MT, Manor U, Lippincott-Schwartz J, Fan CM. Intravital imaging reveals ghost fibers as architectural units guiding myogenic progenitors during regeneration. Cell Stem Cell. 2016;18:243-52 https://doi.org/10.1016/ j.stem.2015.11.005.

25. Kelly R, Alonso S, Tajbakhsh S, Cossu G, Buckingham M. Myosin light chain $3 \mathrm{~F}$ regulatory sequences confer regionalized cardiac and skeletal muscle expression in transgenic mice. J Cell Biology. 1995;129:383-96 https://doi. org/10.1083/jcb.129.2.383.

26. Edmondson DG, Cheng TC, Cserjesi P, Chakraborty T, Olson EN. Analysis of the myogenin promoter reveals an indirect pathway for positive autoregulation mediated by the muscle-specific enhancer factor MEF-2. Mol Cell Biol. 1992;12:3665-77 https://doi.org/10.1128/mcb.12.9.3665. 
27. Yee SP, Rigby PW. The regulation of myogenin gene expression during the embryonic development of the mouse. Gene Dev. 1993;7:1277-89 https:// doi.org/10.1101/gad.7.7a.1277.

28. Grieshammer U, Lewandoski M, Prevette D, Oppenheim RW, Martin GR. Muscle-specific cell ablation conditional upon Cre-mediated DNA recombination in transgenic mice leads to massive spinal and cranial motoneuron loss. Dev Biol. 1998;197:234-47 https://doi.org/10.1006/dbio. 1997.8859.

29. Johnson JE, Wold BJ, Hauschka SD. Muscle creatine kinase sequence elements regulating skeletal and cardiac muscle expression in transgenic mice. Mol Cell Biol. 1989;9:3393-9 https://doi.org/10.1128/mcb.9.8.3393.

30. Jacob F, Monod J. Genetic regulatory mechanisms in the synthesis of proteins. J Mol Biol. 1961;3:318-56 https://doi.org/10.1016/s00222836(61)80072-7.

31. Gorman CM, Moffat LF, Howard BH. Recombinant genomes which express chloramphenicol acetyltransferase in mammalian cells. Mol Cell Biol. 1982;2: 1044-51 https://doi.org/10.1128/mcb.2.9.1044.

32. Andrés V, Walsh K. Myogenin expression, cell cycle withdrawal, and phenotypic differentiation are temporally separable events that precede cell fusion upon myogenesis. J Cell Biology. 1996;132:657-66 https://doi.org/10. 1083/jcb.132.4.657.

33. Guo K, Wang J, Andrés V, Smith RC, Walsh K. MyoD-induced expression of p21 inhibits cyclin-dependent kinase activity upon myocyte terminal differentiation. Mol Cell Biol. 1995;15:3823-9 https://doi.org/10.1128/mcb.15. 7.3823.

34. Zhang P, Wong C, Liu D, Finegold M, Harper JW, Elledge SJ. p21CIP1 and p57KIP2 control muscle differentiation at the myogenin step. Gene Dev. 1999;13:213-24 https://doi.org/10.1101/gad.13.2.213.

35. Ran FA, Hsu PD, Wright J, Agarwala V, Scott DA, Zhang F. Genome engineering using the CRISPR-Cas9 system. Nat Protoc. 2013;8:2281-308 https://doi.org/10.1038/nprot.2013.143.

36. Ryan MD, King AMQ, Thomas GP. Cleavage of foot-and-mouth disease virus polyprotein is mediated by residues located within a 19 amino acid sequence. J Gen Virol. 1991;72:2727-32 https://doi.org/10.1099/0022-131772-11-2727.

37. Kalderon D, Roberts BL, Richardson WD. Smith AE. A short amino acid sequence able to specify nuclear location. Cell. 1984;39:499-509 https://doi. org/10.1016/0092-8674(84)90457-4

38. Rodríguez Cl, Buchholz F, Galloway J, Sequerra R, Kasper J, Ayala R, et al. High-efficiency deleter mice show that FLPe is an alternative to Cre-loxP. Nat Genet. 2000;25:139-40 https://doi.org/10.1038/75973.

39. Gayraud-Morel B, Pala F, Sakai H, Tajbakhsh S. Muscle stem cells, methods and protocols. Methods Mol Biology. 2017;1556:23-39 https://doi.org/10. 1007/978-1-4939-6771-1_2.

40. Yokomizo T, Yamada-Inagawa T, Yzaguirre AD, Chen MJ, Speck NA, Dzierzak E. Whole-mount three-dimensional imaging of internally localized immunostained cells within mouse embryos. Nat Protoc. 2012;7:421-31 https://doi.org/10.1038/nprot.2011.441.

41. Pawlikowski B, Pulliam C, Betta N, Kardon G, Olwin BB. Pervasive satellite cell contribution to uninjured adult muscle fibers. Skeletal Muscle. 2015;5:42 https://doi.org/10.1186/s13395-015-0067-1.

42. Livak KJ, Schmittgen TD. Analysis of relative gene expression data using real-time quantitative PCR and the 2- $\Delta \Delta C T$ method. Methods. 2001;25:4028 https://doi.org/10.1006/meth.2001.1262.

43. Tinevez J-Y, Perry N, Schindelin J, Hoopes GM, Reynolds GD, Laplantine E, et al. TrackMate: an open and extensible platform for single-particle tracking. Methods. 2017;115:80-90 https://doi.org/10.1016/j.ymeth.2016. 09.016

44. Schindelin J, Arganda-Carreras I, Frise E, Kaynig V, Longair M, Pietzsch T, et al. Fiji: an open-source platform for biological-image analysis. Nat Methods. 2012;9:676-82 https://doi.org/10.1038/nmeth.2019.

45. Team RC. R: a language and environment for statistical computing. $R$ Foundation for Statistical. 2014. http://www.R-project.org/.

46. Wickham H. ggplot2, elegant graphics for data analysis. 2009. https://doi. org/10.1007/978-0-387-98141-3.

47. Cheng TC, Hanley TA, Mudd J, Merlie JP, Olson EN. Mapping of myogenin transcription duringembryogenesis using transgenes linked to the myogenin control region. J Cell Biol. 1992;119:1649-56. https://doi.org/10. 1083/jcb.119.6.1649.

48. Gattazzo F, Laurent B, Relaix F, Rouard H,Didier N. Distinct Phases of Postnatal Skeletal Muscle Growth Govern the ProgressiveEstablishment of
Muscle Stem Cell Quiescence. Stem Cell Rep. 2020. https://doi.org/10.1016/j. stemcr.2020.07.011.

49. Gayraud-Morel B, Chrétien F, Tajbakhsh S. Skeletal muscle as a paradigm for regenerative biology and medicine. Regen Med. 2009;4:293-319 https://doi. org/10.2217/17460751.4.2.293.

50. Hardy D, Besnard A, Latil M, Jouvion G, Briand D, Thépenier C, et al. Comparative study of injury models for studying muscle regeneration in mice. Plos One. 2016;11:e0147198 https://doi.org/10.1371/journal.pone. 0147198.

51. Konagaya Y, Takakura K, Sogabe M, Bisaria A, Liu C, Meyer T, Sehara-Fujisawa A, Matsuda M, Terai K. Intravital imaging reveals cell cycle-dependent myogenic cell migration during muscle regeneration. Cell Cycle. 2020 19(22):3167-81. https://doi.org/10.1080/15384101.2020.1838779.

52. Lau J, Goh CC, Devi S, Keeble J, See P, Ginhoux F, et al. Intravital multiphoton imaging of mouse tibialis anterior muscle. Intravital. 2016;5: e1156272 https://doi.org/10.1080/21659087.2016.1156272.

53. Petkova MV, Stantzou A, Morin A, Petrova O, Morales-Gonzalez S, Seifert F, et al. Live-imaging of revertant and therapeutically restored dystrophin in the DmdEGFP-mdx mouse model for Duchenne muscular dystrophy. Neuropath Appl Neuro. 2020; https://doi.org/10.1111/nan.12639.

\section{Publisher's Note}

Springer Nature remains neutral with regard to jurisdictional claims in published maps and institutional affiliations.

\section{Ready to submit your research? Choose BMC and benefit from:}

- fast, convenient online submission

- thorough peer review by experienced researchers in your field

- rapid publication on acceptance

- support for research data, including large and complex data types

- gold Open Access which fosters wider collaboration and increased citations

- maximum visibility for your research: over $100 \mathrm{M}$ website views per year

At BMC, research is always in progress.

Learn more biomedcentral.com/submissions 